\title{
Intrauterine device removal from the sigmoid colon during a screening colonoscopy
}

Ana García-Rodríguez, Marco Álvarez,

An intrauterine device (IUD) is a highly effective method of contraception and is associated with few side effects; however, uterine perforation and migration of the IUD to adjacent organs including the colon have been reported.

A 54-year-old woman without relevant medical history underwent a screening colonoscopy. A cylindrical foreign body measuring $25 \times 1 \mathrm{~mm}$ and penetrating the wall of the sigmoid colon was detected, and was easily removed using a snare ( $\bullet$ Fig. 1). The foreign body was later confirmed to be an IUD. The woman remained asymptomatic but a computed tomography scan was performed to rule out complications and no sign of perforation was found. Subsequently, the woman reported that she had undergone insertion of an IUD a few months before falling pregnant at the age of 34. She explained that the IUD had not been found inside her uterus when pregnancy ultrasound scans were performed but, despite that, the woman had given birth naturally. Finally, the patient was discharged and was scheduled to undergo the screening colonoscopy, during which a normal mucosal defect closure was observed.

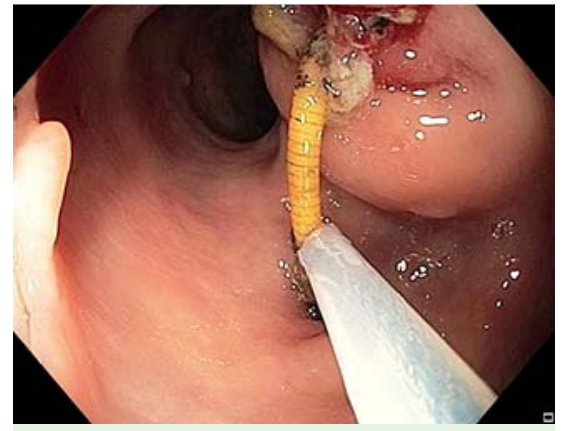

Fig. 1 A routine colonoscopy revealed an intrauterine device embedded in the sigmoid colon of a 54-year-old woman. The device was removed with a snare.

IUD migration to the colon usually requires surgical intervention. Endoscopic IUD removal has been reported from the rectum, which is mainly extraperitoneal. However, we have only found one case involving the sigmoid colon where clips were used to close the wall defect [1]. In circumstances where a thin foreign body has been embedded in the bowel wall for a long time, we believe that endoscopic removal is safe because the fistulous tract collapses spontaneously and does not require mucosal defect closure or additional interventions.

\section{Agustin Seoane}

Endoscopy Unit, Hospital del Mar,

Barcelona, Spain

\section{Reference}

1 Lee J, Park KS, Kim ES et al. Removal of lost intrauterine device by colonoscopy after a successful full-term delivery (with video). Gastrointest Endosc 2010; 72: 898 -900

\section{Bibliography}

DOI http://dx.doi.org/

10.1055/s-0034-1392973

Endoscopy 2015; 47: E446

(c) Georg Thieme Verlag KG

Stuttgart · New York

ISSN 0013-726X

Corresponding author

\section{Ana García-Rodríguez, MD}

Endoscopy Unit

Hospital del Mar

Passeig Marítim 25-25

Barcelona 08003

Spain

Fax: +34-932-483376

anagrod4@gmail.com 